\title{
Place of phraseology in the study of foreign languages (on the example of Russian as a foreign language)
}

\section{[Место фразеологии в изучении иностранных языков (на примере русского как иностранного)]}

\author{
Larisa Borisovna Katsyuba - Kholisakhon Eshmatovna Ismailova - Olga \\ Victorovna Bondareva
}

DOI: 10.18355/XL.2020.13.02.07

\begin{abstract}
The paper presents a description of the methodology and some results of the use of phraseological units, proverbs, sayings to improve the efficiency of the mastering of Russian as a foreign language. The article describes the use of phraseological materials of the teacher of Russian as a foreign language in the classroom with students from different countries. Analysis of the results of the use of phraseological units, proverbs, sayings showed the prospects of the use of phraseological units for the development of students phonetics, vocabulary, grammar, as well as the development of students ' ability to listen, read and write in Russian.
\end{abstract}

Key words: phraseology, cultural linguistics, Russian as a foreign language, proverb, saying

\begin{abstract}
Аннотация
В работе представлено описание методики и некоторые результаты применения фразеологизмов, пословиц, поговорок, чистоговорок для повышения эффективности освоения русского языка как иностранного (РКИ). Описано применение фразеологических материалов преподавателя русского языка как иностранного на занятиях со студентами из разных стран. Анализ результатов применения фразеологизмов, пословиц, поговорок, чистоговорок показал перспективность применения фразеологизмов для освоения студентами фонетики, лексики, грамматики РКИ, а также развитие у студентов способности аудирования, чтения и письма на русском языке.

Ключевые слова: фразеология, лингвокультурология, русский язык как иностранный, пословица, поговорка
\end{abstract}

\section{Введение}

Фразеологическая тема в изучении иностранных языков, в частности, русского языка как иностранного (РКИ), продолжает разработку культурологического подхода в лингводидактике. Многие исследователи (Pavlovskaya, 2000; Sokol, 2006) отмечают ценность эстетически значимой формы фразеологизмов и пословиц, их роль в формировании коммуникативной компетенции, поскольку «успешный диалог в межкультурной коммуникации невозможен без познаний в области лингвокультуры. Именно поэтому современная лингводидактика исходит из того, что в основе иноязычной коммуникативной компетентности лежат лингвокультурологическая и лингвистическая компетенции» (Farkhutdinova, 2013). Вопрос о включении фразеологического материала как части лексико-фразеологической системы в содержание процесса обучения РКИ преподаватели-практики не считают остро дискуссионным, поскольку по достоинству оценили лингвокультурологический, страноведческий, лингводидактический потенциал этих единиц: «в человеческом обществе и, в частности, в речевом общении они 
(фразеологические единицы - Авторы) выполняют самые разнообразные функции: моделируют ситуацию, поучают, становятся магическими символами, развлекают, помогают наладить контакт или прервать его, дают возможность прогнозировать будущее и т.д. Кроме того, они имеют эстетически значимую форму, поскольку создавались по особым правилам народной культуры. Таким образом, пословицы и поговорки становятся бесценным материалом для формирования лингвокультурологической компетенции» (Farkhutdinova, 2013).

Необходимо сделать замечание о том, что в настоящей работе мы придерживаемся широкого понимания фразеологии. Говоря о фразеологическом материале, мы оперировали данными о фразеологии, которая наряду с фразеологизмами изучает устойчивые фразы разных структурных типов, в том числе пословицы и поговорки. Считаем нужным также отметить, что фразеологический материал (пословицы, поговорки, фразеологизмы) с определенными оговорками принадлежит к сфере идиоматики (KirshenblattGimblett, 1981; Dundes, 1981; Cram, 1994; Katsyuba, 2013; 2018a), если учесть, что идиомами в отечественной и зарубежной традициях (Seidl, 1997; Akhmanova, 2012; Baranov, 2007) называют устойчивые сочетания; многокомпонентные выражения с целостным значением, которое не может быть восстановлено из индивидуальных значений слов-компонентов; фразеологизмы.

\section{Методы}

Широта диагностического аппарата работы определена избранными методами. Были использованы общелогические методы и приемы исследования, основанные на изучении закономерностей и раскрытии объективных законов языка:

- анализ и синтез,

- обобщение,

- индукция и дедукция,

и специальные лингвистические методы:

- лингвистическое наблюдение,

- филологический анализ учебно-научного текста,

- структурно-семантическое и прагматическое описание,

- индуктивный метод анализа от конкретных языковых фактов к установлению системных отношений между ними и обобщения на этой основе теоретических положений и выводов.

Кроме того, использовался метод педагогического наблюдения:

- наблюдение за учебным процессом.

Цель - анализ возможностей применения фразеологического материала на разных этапах образовательного процесса и определение значимости фразеологических единиц для формирования и развития у иностранных студентов коммуникативной и лингвокультурологической компетентности.

\section{Задачи}

Фразеологические единицы играют важную роль в реализации современной коммуникации носителя русского языка; они частотны по употреблению, имеют объемную семантику и коннотацию. Однако несмотря на такие языковые особенности работа с данными единицами в иностранной аудитории встречает ряд трудностей: проводится ограниченно по времени (или не проводится совсем), нерегулярно, бессистемно и т.п. Действительно, работа преподавателя по включению фразеологического фонда в активную часть лексикона иностранца трудоемка. Вот некоторые задачи, которые в этой связи мы пытаемся решить теоретически и практически:

XLinguae, Volume 13 Issue 2, April 2020, ISSN 1337-8384, ISSN 2453-711X 
- определение этапа введения фразеологического материала в содержание учебного процесса;

- объем фразеологического материала, который должен стать активной и пассивной (уровень понимания) частью лексикона;

- репрезентация материала;

- место представленного материала в учебнике и тексте;

- система упражнений, направленная на исследование семантизации, грамматикализации и лингвокультурологических особенностей данных единиц и их активную реализацию в речи.

\section{Методика и обсуждение}

Рассматривая фразеологический материал в лингво-образовательном контексте, опираясь на собственный опыт преподавания, мы отметили значение фразеологии уже на фонетическом этапе - в формировании слухопроизносительных и артикуляционных навыков при изучении русского языка как иностранного. Работа с устойчивыми единицами: пословицами, поговорками, чистоговорками и скороговорками начинается на этапе вводного фонетико-грамматического курса, т.е. в первые десять дней знакомства с русским языком, при постановке трудных для иностранцев русских звуков (например, [ы], [б], шипящих звуков [щ], [ц], [ч], [ш], парных звуков по твердости-мягкости [л], [р], и др.), при отработке навыков интонирования. Для этих целей подойдут специальные предложения - чистоговорки: Крыса в риге грызла рис; На дворе трава, на траве дрова. Раз дрова, два дрова, три дрова; Дед делил дыню: дольку - Диме, дольку - Дине; Чуть что - тетя Тютчева читает; Купили Валерику и Вареньке варежки и валенки; Черепаха, не скучая, час сидит за чашкой чая; Два щенка щека к щеке грызли щетку в уголке и др.

Говоря о чистоговорке, нужно сказать несколько слов о дефиниционном аспекте этого нелингвистического термина. Современные русские лингвистические словари (Yartseva, 1998; Akhmanova, 2012; Polivanov, 2015) не дают определение чистоговорки. Опыт работы и анализ специальной литературы позволил нам сформулировать рабочее определение понятия: чистоговорка - специально созданное ритмически выдержанное предложение с набором труднопроизносимых звуков и звукосочетаний, употребляемое в качестве фонетического упражнения, тренажера. Зачастую чистоговоркой может служить пословица.

О лингводидактической функции пословиц в постановке и коррекции некоторых звуков, например, [л'] мягкого, писала преподаватель-практик С.П. Розанова: «полезно повторять русские пословицы, крылатые выражения (Сколько лет - сколько зим! Тише едешь - дальше будешь! Дальше в лес больше дров! и т.д.)» (Rozanova, 2015). Автор учебного пособия отмечала важность устойчивых единиц, а также поэтических форм в выработке так называемого «слухо-двигательного динамического стереотипа» у студентовиностранцев, позволяющего беспрепятственно различать, слышать русскую речь, говорить по-русски без акцента: «разучивание песен, стихов, поговорок развивает «чувство русского языка», формирует долговременные навыки, стимулирует и мобилизирует механизмы запоминания» (Rozanova, 2015). Действительно, в фонетической практике использование фразеологического материала является достаточно продуктивным. Однако главная задача преподавателя на начальном этапе изучения русского языка корректно отобрать несложные с точки зрения лексики и грамматики коммуникативноориентированные единицы, которые бы представляли определенную ценность для студента. В начале работы объем этих единиц должен быть минимальным.

Как справедливо отмечено, «при обучении любому иностранному языку необходимо в начале курса хорошо изучать лексику. Именно лексика, 
взаимодействуя в речи с грамматикой и фонетикой, является ведущим средством речевого общения в устной и письменной формах. Лексика неразрывно связана с грамматической системой языка, одно без другого не существует, и лексика оказывает огромное влияние на грамматику. Обучение лексике - это не просто заучивание новых слов, а усвоение имеющихся между ними в языке фонетических, грамматических, смысловых и ассоциативных связей» (Ismailova, 2018b). Фразеологические единицы как специфическая часть лексикона языка в начале изучения русского языка как иностранного вводятся постепенно на уровне понимания, закрепляясь в речи в качестве пассивного запаса.

На начальном этапе в процессе прохождения учащимися вводного фонетико-грамматического курса первые пословицы (с переводом) появляются в качестве иллюстративного материала начиная с шестого-седьмого урока (по прошествии 36 часов аудиторных занятий): Сначала думай - потом говори; Сначала думай - потом делай; И Москва не сразу строилась; Мой дом - твой дом; Тише едешь - дальше будешь; Яйца курииу не учат; Повторение - мать учения; Лучше поздно, чем никогда. В работе с числительными актуализируются пословицы: Одна голова хорошо, а две лучше; Не имей сто рублей, а имей сто друзей; Семь раз отмерь - один раз отрежь.

Знакомство с русскими пословицами продолжается и на этапе работы с первыми обиходно-бытовыми глаголами, связанными с тематикой повседневной жизни: читать, знать, делать, работать, говорить, любить, жить, быть. Запоминая формы глаголов, работая со словарем глаголов (Shustikova, 2012) и основанной на его структуре глагольной тетрадью, студенты исследуют контекстное употребление глагольных лексем. Здесь в качестве примеров выступают пословицы: Кто много читает, тот много знает; Кто хочет много знать. тому надо мало спать; Долго думай, да быстро делай; Кто не работает, тот не ест; Мало говори, да много делай; $Б у д ь$ что будет! и др. Фразеологические единицы выступают не только образцами построения отдельных синтаксических конструкций современной речи, но и являются ее составной частью. На данном этапе могут быть реализованы разные возможности вопросно-ответной деятельности и самостоятельной работы. На основе работы с глаголами в пословицах актуальны первые дискуссии, активно направленные на развитие речи. Например, студенты получают задание:

- Подумайте и скажите, почему так говорят: Кто много читает, mom много знает?

(Ответы студентов, изучающих язык в течение первых десяти дней, приведены с соблюдением оригинальной грамматики: Книга - (это) хорошо; Это умный человек (студент); Книги надо много (читать); Умный студент - это хорошо; Книга(-и) много учат и т.п.).

На наш взгляд, полноценная серьезная работа с фразеологизмами и пословицами начинается на среднем этапе обучения, со второго семестра довузовской программы, и продуктивно развивается на всех последующих этапах вузовского обучения, когда студенты, магистранты, аспиранты наработали более высокий уровень владения русским языком. Активная работа с текстами по общему владению языком, в которых встречаются фразеологизмы, пословицы, идиомы, может проходить во втором семестре довузовского этапа. Работа с текстом - это новая ступень в познании языка, поскольку «богатейший лингводидактический и психолингвистический потенциал текста дает возможность использовать его не только как материал для наблюдений и анализа функционирования языковых - лексических и грамматических единиц и как основной источник страноведческой и

XLinguae, Volume 13 Issue 2, April 2020, ISSN 1337-8384, ISSN 2453-711X 
культуроведческой информации, но и как предметно-содержательную основу для речи, а главное - как стимул для развития и совершенствования всех речевых умений» (Khavronina, 2013).

Рассмотрим фрагмент учебного материала занятия по теме «Человек», включающей разделы «Внешность и характер человека», «Мой дом - моя крепость»; «Моя семья»; «Кем быть? Где работать? Чем заниматься?»; «Мои друзья - мое богатство» и т.д. Представленные для работы небольшие тексты диалогического и монологического характера способствуют отработке как общеязыковой, так и фразеологической компетенции.

Например, текст «Моя семья»:

«Любому человеку нужна семья, в которой самое главное - защита, доверие, доброта, любовь. И русский человек не исключение. Семейные ценности важны для каждого человека, поэтому в русском языке вы можете найти большое количество пословиц, которые говорят о роли семьи: $B$ семье $u$ каша гуще; Семейное согласие всего дороже; Вся семья вместе, так и душа на месте; Не нужен и клад, коли в семье лад; Русский человек без родни не живёт...

Создание семьи - один из самых важных этапов в жизни любого человека, шаг очень ответственный. Каждая семья - это свой маленький мир, мир близких, но сложных взаимоотношений. Люди ищут в браке счастья, взаимопонимания, поддержки. Но, прежде чем начать вить гнездо (устраивать свою семейную жизнь, создавать домашний уют), молодые люди вступают в брак (женятся, выходят замуж, создают семью). Перед этим мужчина делает предложение женщине, просит её руки (и сердия), т.е. предлагает ей стать его женой.

Пример: Вчера мой друг сделал мне предложение! Я ответила ему, что согласна...

И, конечно, главная ценность в семье - дети. Известно, что родители часто любят детей больше, чем дети родителей. Но родители не становятся от этого менее счастливыми, ведь для них ребёнок - свет в окошке. Так говорят о самом дорогом, любимом, с кем связаны лучшие надежды.

Пример: Для моей матери я всегда был светом в окошке...

Веками жизнь русского человека состояла из трёх периодов: «расту сам - ращу детей - воспитываю внуков». И для каждого периода самым главным были и остаются семья, любовь, уважение и поддержка» (Chepkova, 2015).

Период изучающего чтения включает в себя элементы работы с новой лексикой и фразеологией, разбор семантико-грамматических особенностей фразеологических единиц. Далее задания по тексту включают работу по переводу пословиц и фразеологизмов на родной язык, подборку подходящих эквивалентов; понимание прямого и переносного смысла фразеологических единиц, применение новых пословиц в устной речи; узнавание новых единиц, исправление ошибок в неверном употреблении единиц; составление пословиц и фразеологизмов из разрозненно данных лексем, восстановление формы фразеологизмов. В качестве самостоятельного творческого домашнего задания можно предложить нарисовать фразеологизмы с целью разъяснения истории создания, глубинного смысла, сопоставления с прямым значением. При этом форма предъявления фразеологического материала может быть традиционной и интерактивной (о некоторых интерактивных методах работы на занятиях по РКИ см. (Ismailova, 2018a).

Домашнее задание студентов помимо традиционных заданий на отработку грамматических и лексических навыков упражнения по фразеологии также может включать в себя упражнения на составление обзоров на тему «Из истории одного фразеологизма» (например, тише воды, ниже травы; волка 
ноги кормят, семеро одного не ждут, белая ворона крокодильи слёзы, глаза разбегаются золотые руки, (спать) без задних ног и др.) и его визуальное представление, при этом художественные навыки учащихся не имеют решающего значения.

Как показывает практика преподавания, «предоставление учащимся на занятии подходящих готовых фразеологизмов, с разъяснением их смысла и сопоставлением переносного значения с прямым делает задание «Нарисуй фразеологизм» востребованным и интересным. Включенные в творческие задания фразеологизмы впоследствии входят в так называемую базу данных фразеологического занятия, а рисунки фразеологизмов участвуют в выставке фразеологических работ на заключительном занятии» (Katsyuba, 2018b: 556).

Примеры выполненных студентами работ можно увидеть на рисунках, представленных ниже.

\section{Meribent Ha yxo hacmynun}

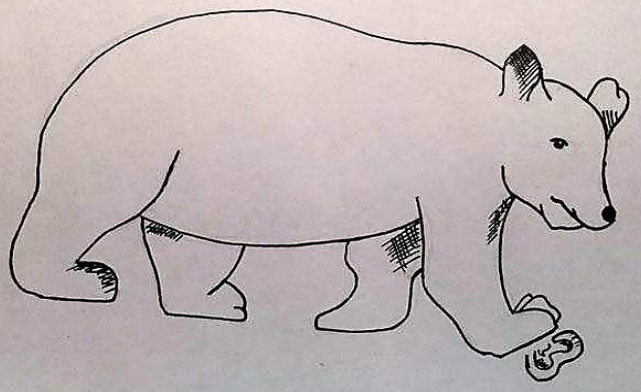

Pagrunobuz $\operatorname{cin} 2-11$

Рисунок 1: «медведь на ухо наступил»

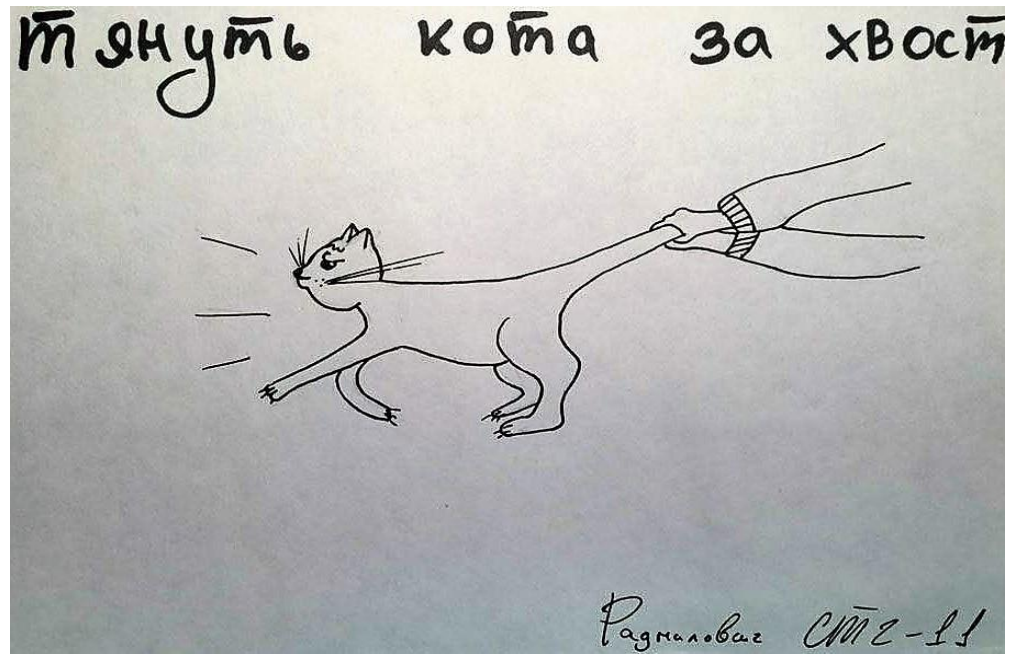

XLinguae, Volume 13 Issue 2, April 2020, ISSN 1337-8384, ISSN 2453-711X 
Рисунок 2: «тянуть кота за хвост»

ПИСА̄̄

\section{KaK \\ kypuya АAחOŪ}

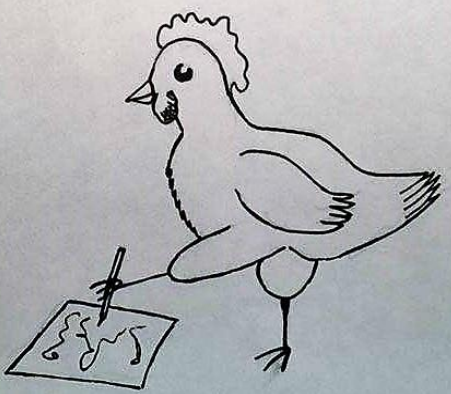

Pagrunbur Cìr -11

Рисунок 3: «писать как курища лапой»

\section{Pasbecum̃ ywu}

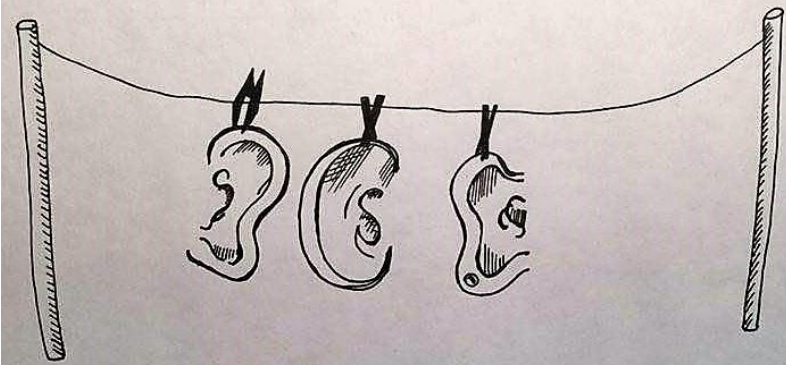

Pagrunobur $c \bar{m} \Gamma-1$

Рисунок 4: «развесить уши» 

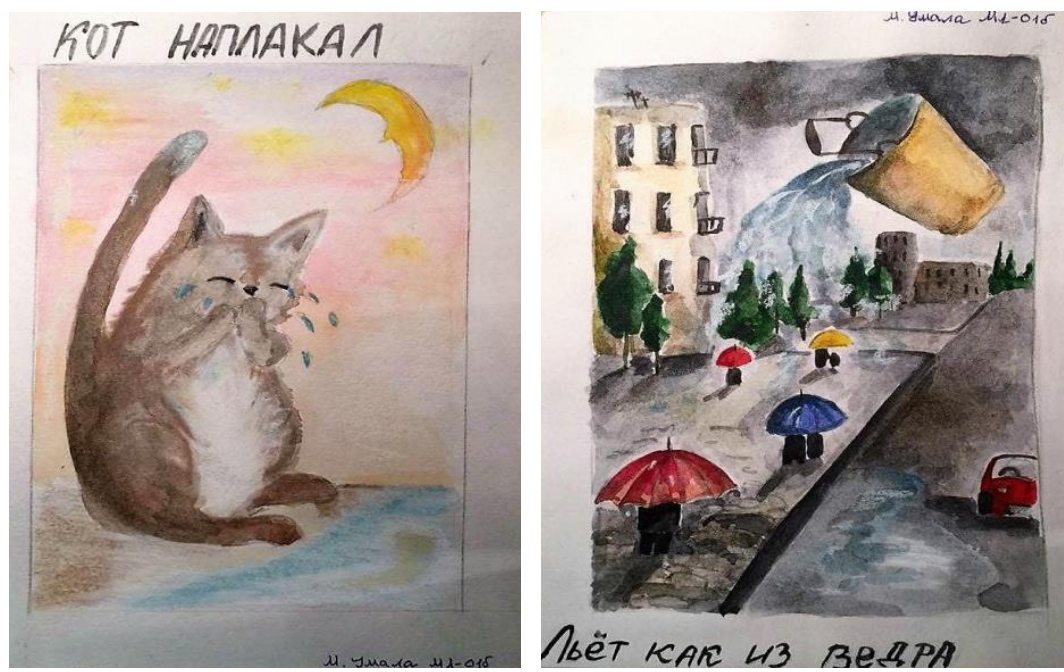

Рисунок 5: «кот наплакал»

Рисунок 6: «льёт как из ведра»

Необходимо подчеркнуть, что интенсивная целенаправленная фразеологическая работа будет продуктивна в группах с достаточно высокой лингвокультурной адаптацией, которая среди прочего зависит от уровня владения языком и выбранной специальности (например, работа со студентами и аспирантами гуманитарных специальностей). В таких группах можно использовать фразеологические ресурсы в большем объеме и, как показывает практика, часть коммуникативно значимого для студента фразеологического материала, при постоянно обновляющемся материале и сбалансированной системе упражнений, закрепляется в качестве активного запаса.

\section{Обсуждение результатов}

Обсуждая место фразеологии в изучении иностранных языков (на примере русского как иностранного) можно высказать следующие положения. Поэтапное введение фразеологического материала в содержание учебного процесса - от первых дней до любого уровня владения - благоприятно сказывается на реализации познавательного аспекта обучения иностранцев иноязычной для них русской лингвокультуре как части русской культуры. Важнейшими задачами для преподавателя на начальном этапе являются стадиальная организация фразеологического материала, строгий отбор актуальных фразеологический единиц, коммуникативно значимых для студента, подбор системы упражнений, нацеленных на исследование семантикограмматических особенностей и лингвокультурологической специфики данных единиц и их активную реализацию в речи.

\section{Заключение}

Результаты проведенных занятий с применением фразеологизмов и пословиц по разным темам общего владения РКИ и их анализ показали, что включение такого лингвокультурологического материала в учебную деятельность повышает эффективность обучения РКИ и дает возможность реализации на фонетическом рубеже освоения языка как одного из весомых моментов, участвующих в выработке русского артикуляционно-слухо-

XLinguae, Volume 13 Issue 2, April 2020, ISSN 1337-8384, ISSN 2453-711X 
двигательного динамического стандарта. На этапе предвузовского рубежа фразеологизмы, пословицы, поговорки, чистоговорки в основном активно применяются в лексико-грамматических темах в качестве дополнительного иллюстративного материала и развивают навыки речевого общения, что также способствует формированию социолингвистической и лингвокультурологической компетенций. Использование русского фразеологического фонда на занятиях РКИ открывает новые возможности для аудиторной работы и самообразования студентов.

The publication has been prepared with the support of the "RUDN University Program 5-100".

Публикация подготовлена при поддержке Программы РУДН «5-100».

\section{Bibliographic references}

AKHMANOVA, O. S. 2012. Dictionary of linguistic terms. Moscow: Book on demand. ISBN 978-5-458-52192-5.

BARANOV, A. N. etc. 2007. Dictionary-thesaurus of modern Russian idiomatics: about 8000 idioms of the modern Russian language. Moscow: The World of Encyclopedias Avanta +. ISBN 978-5-98986-139-2, 978-5-98986-143-9.

CHEPKOVA, T. P. - MARTYNENKO, Y. B. - STEPANYAN, E. V. 2015. Russian phraseological units. We learn and teach: a textbook for universities. Moscow: Flinta; Nauka. ISBN 978-5-9765-1733-2.

CRAM, D. 1994. The Linguistic Status of the Proverb. In: Wise Words: Essays on the Proverb. Ed. W. Mieder. New York: Garland Publishing, Inc., pp. 73-98.

DUNDES, A. 1981. On the Structure of the Proverb. In: The Wisdom of Many: Essays on the Proverb. Edited by Wolfgang Mieder and Alan Dundes. Madison, WI: The University of Wisconsin Press, pp. 43-64.

FARKHUTDINOVA, F. F. 2013. Small genres of the folklore in the development of the foreign communal competence of foreign students-philologists. In: Genry-style approach in teaching Russian language and culture of speech. XI Ushakovsky readings. Collection of scientific articles and methodical recommendations on the materials of the All-Russian Scientific and Practical Conference. Publisher: Ivanovo State University (Ivanovo), pp. 383-390.

ISMAILOVA, Kh. E. - ARZUMANOVA, R. A. - KATSYUBA, L. B. PSHENICHNIKOVA, A. Y. 2018. Methodological foundations of teaching vocabulary to foreign students-nonphilologists by means of computer technologies (initial stage of training). In: Revista ESPACIOS, vol. 39. n. 29, p. 8. ISSN 07981015. ISMAILOVA, Kh. E. - BONDAREVA, O. V. 2018. Learning the vocabulary of Russian as a foreign language within the elementary level through Quizlet.com. In: XLinguae, vol. 11, issue 3, eISSN 2453-711X 89. ISSN 1337-8384.

KATSYUBA, L. B. 2013. Determination of paremia as a unit of language and communication . In: Bulletin of the Chelyabinsk State University. Series «Philology. Art History», vol. 73, n. 1 (292), pp. 53-57. ISSN 1994-2796.

KATSYUBA, L. B. 2018. The verb's face in Russian proverbs: semantic-grammatical and linguacultural aspects: monograph (Ed.) A. M. Chepasova. Moscow: Flinta. ISBN 978-5-9765-3799-6.

KATSYUBA, L. B. 2018. Work with phraseological material at the lessons of Russian as a foreign language. In: Teaching Russian as a foreign language in higher education: experience and prospects: collection of scientific articles. Moscow: MGIMO-University, pp. 552-558. ISBN 978-5-9228-1842-1.

KHAVRONINA, S. A - GULYAEVA, I. V. 2013. Methodology of teaching Russian to foreigners and psycholinguistics. In: Bulletin of the Peoples' Friendship University of Russia, n. 2, pp. 11-16. 
KIRSHENBLATT - GIMBLETT, B. 1981.Toward a Theory of Proverb Meaning. The Wisdom of Many: Essays on the Proverb. (Eds.) Wolfgang Mieder, Alan Dundes. Madison, WI: The University of Wisconsin Press, pp. 111-122.

PAVLOVSKAYA, L. G. 2000. Russian phraseology as a fragment of the language picture of the world by the acquisition of Latvian students: thesis for the degree of doctor of pedagogical sciences: 13.00.02; (place of conservation: Pushkin State Russian Language Institute). Moscow.

POLIVANOV, E. D. 2015. Dictionary of linguistic and literary terms terms. Moscow: The book house «LIBROKOM». ISBN 978-5-397-04590-2.

ROZANOVA, S. P. 2015. For teachers of Russian as a foreign language: one hundred and forty-seven useful tips. Moscow: Flinta; Nauka. ISBN 978-5-9765-2043-1.

SEIDL, J. English idioms. Oxford. 1997.

SHUSTIKOVA, T. V - ATABEKOVA A. A. - KURMAEVA N. M. 2016. Russian verbs. Forms and contextual use: a textbook. Moscow: Flinta; In: Nauka. ISBN 978-589349-434-1

SOKOL, M. A. 2006. Russian phraseological units as a means of forming the communicative competence of foreign students-non-philologists: thesis for the degree of candidate of pedagogical sciences: 13.00.02; (place of conservation: Nizhny Novgorod state pedagogical University). Nizhny Novgorod.

YARTSEVA, V. N. 1998. Linguistics. Large Encyclopaedic Dictionary. Moscow: The Great Russian Encyclopedia.

Words: 3133

Characters: 24605 (13,67 standard pages)

Associate Professor Larisa Borisovna Katsyuba

Department of Russian language №2

The faculty of Russian language and General educational disciplines

PEOPLES' FRIENDSHIP UNIVERSITY OF RUSSIA (RUDN University)

6, Miklukho-Maklay street

117198, Moscow

Russian Federation

larrakatz@yandex.ru

katsyuba-lb@rudn.university

Associate Professor Kholisakhon Eshmatovna Ismailova

Department of Russian as a Foreign Language

Institute of Fundamental Education

MOSCOW STATE UNIVERSITY OF CIVIL ENGINEERING

26, Yaroslavskoye shosse, 129337, Moscow

Russian Federation

holisa1967@mail.ru

Ismailova KHE@mgsu.ru

Assistant Professor Olga Victorovna Bondareva

Department of Russian language №2

The faculty of Russian language and General educational disciplines

PEOPLES' FRIENDSHIP UNIVERSITY OF RUSSIA (RUDN University)

6, Miklukho-Maklay street

117198, Moscow

Russian Federation

logiolya@yandex.ru

bondareva_ov@rudn.university

XLinguae, Volume 13 Issue 2, April 2020, ISSN 1337-8384, ISSN 2453-711X 